\title{
DESIGN AND CONSTRUCTION OF A LAB-ON-A-PAPER FOR LOW-COST AND DISPOSABLE POINT-OF CARE DIAGNOSTICS
}

\author{
Afnidar $^{1}$ dan Bambang Kuswandi ${ }^{2}$ \\ ${ }^{1}$ Department of Chemical Education, Open University, Jakarta, Indonesia \\ ${ }^{2}$ Chemo and Biosensors Group, Faculty of Pharmacy, University of Jember, Jember 68121, Indonesia \\ *email: afnidar@gmail.com
}

Diterima 5 Januari 2016 disetujui 7 Maret 2016

\begin{abstract}
This paper presents a low-cost and disposable paper based microfluidic analysis system for point-ofcare diagnostics. Detection is achieved by using a colorimetric or visual indicator. Immobilized specific reagent or enzymes designed for the parameter under consideration act as capture molecules on the surface of the detection zone. The sensor is integrated into a microfluidic system made of paper (cellulose). An additional component of the analysis system is a capillary unit which is used to introduce the analyte to the detection zone. For this purpose well-defined, millimeter-sized channel, comprising hydrophobic polymer bounded onto hydrophilic paper was created. Then the detection zone was coated with a sensitive reagent layer as a sensor region. The paper based microfluidics also called lab on paper, has been fabricated using screen printing technology as the basis for low-cost, disposable, portable and technically simple fabrication for mass production. Microfluidics in paper make it feasible to run single, dual or even multiple clinical analyses on one strip of paper while still using only small volumes of a single sample. The capability of lab on paper for detection of importance clinical analyte protein in urine, saliva and blood samples has been demonstrate successfully. Lab on paper as a diagnostic system is small, disposable, and easy to use and requires no external equipment, reagents, or power sources. This kind of diagnostic system is attractive for use in developing countries, in the field, or as a low-cost alternative to more-advanced technologies already used in clinical diagnostics.
\end{abstract}

Keywords: Lab-on-a-paper, Point-of-care, Visual detection, Clinical diagnostic, Disposable sensor

\section{Introduction}

The analysis of biological fluids in clinical practices is necessary for monitoring the health condition of peoples [1-2], but these measurements are difficult to implement in remote regions such as those found in less-industrialized countries, in the village and urban area, in emergency situations, or in home health-care settings [3]. Currently, conventional laboratory instruments provide quantitative measurements of biological samples, but they are unsuitable for these situations as they are large, expensive, and require trained personnel and considerable volumes of biological samples [2]. Other platforms for clinical analysis provide alternatives to more-expensive instruments, $[4-5,6]$ but the need remains for a platform that uses small volumes of sample and that is sufficiently inexpensive to be widely used, particularly in lessdeveloped regions and countries. Therefore, there is an urgent need for new technologies to enable inexpensive, convenient and rapid screening in clinical analysis.

Diagnostics tests that could be employed in this direction at the point-of- care, for example, doctors' and dentists' offices, and operated without extensive training or expertise are of special interest. Lab-on-a-chip (LOC) $[7,8]$ the miniaturization of fluidic networks for chemical and biochemical processing and analysis - offers a means for mass-produced, low-cost, single-use (disposable) devices for screening and diagnostics, providing easily interpreted test results in a time frame of 10 to $60 \mathrm{~min}$. Ideally, these lab-on-a-chip diagnostics systems would use 10 to $1,000 \mathrm{pL}$ of various types of clinical specimens including oral fluids, whole blood, serum, or urine, collected by minimally invasive methods. In general, the anticipated benefits of LOC for clinical analysis derive from the use of small sample volumes, 
automated operation, short processing times, and near real-time reporting of results, reduced reagent consumption, reproducibility and consistency, reduced exposure to hazardous materials and infectious agents, minimal risk of sample contamination, convenient disposal, and low cost.

In this direction, we believe that paper based LOC may be one of the low- cost sensor platforms available for developing clinical diagnostics. We develop diagnostic kits based on paper by patterning paper to form defined areas of hydrophilic paper separated by hydrophobic lines or "walls" using screen printing technology at both sides; therefore, these patterns provide spatial control of biological fluids and enable fluid transport, without pumping, owing to capillary action in the millimeter-sized channels produced. Patterns in paper make it feasible to run multiple clinical analyses on one strip of paper while still using only small volumes of a single sample. Furthermore, in a less developed technology lab setting, patterning paper with screen printing technology is convenient and useful for prototyping these devices in new micro-patterning technology.

\section{Experiment}

Paper based LOC fabrication. The filter paper (Whatman) has been patterned with rubber base ink ('Sunrise", MD type, C.V.Cipta Warna Jaya) in both side using screen printing technology as shown in Figure 1 (LOC size $160 \times 200 \mathrm{~mm}$, for design $A$ and $B$ ). After printing, the patterned paper was dried for 3 min using hair dryer. The paper was more hydrophobic after it was patterned, while the un-patterned side was still hydrophilicity region of the paper. After this process, the patterned paper can be used as LOC for clinical analysis by adding appropriate reagents to the test areas (Figure 1-2).

The paper based LOC has been demonstrated by detecting protein individually. However, the surface of the paper chip should also be suitable for measuring many other analytes as well. The protein sensor is based on the color change of tetrabromophenol blue (TBPB) when it ionizes and binds to proteins [9], a positive result in this case is indicated by a color change from yellow-green to blue. For the protein detection, $0.3 \mathrm{~mL}$ of a 250 $\mathrm{mM}$ citrate buffer solution $(\mathrm{pH} 1.8)$ were spotted in a well and then layered a $3.0 \mathrm{mM}$ solution $(0.3 \mathrm{~mL})$ of tetrabromophenol blue (TBPB) in 95\% ethanol over the citrate buffer solution. The spotted reagents were allowed to air dry at room temperature.

Measurement procedure. The working performance of paper based LOC was tested by measuring artificial sample uric acid (bovine serum albumin (BSA) in clinically relevant ranges by dipping the bottom of each LOC in a pre-made test solution $(5 \mathrm{~mL}$; Figure 3$)$. An artificial urine solution was prepared according to Brooks and Keevil [10]. The artificial urine solution was 1.1 $\mathrm{mM}$ lactic acid, $2.0 \mathrm{mM}$ citric acid, $25 \mathrm{mM}$ sodium bicarbonate, $170 \mathrm{mM}$ urea, $2.5 \mathrm{mM}$ calcium chloride, $90 \mathrm{mM}$ sodium chloride, $2.0 \mathrm{mM}$ magnesium sulfate, $10 \mathrm{mM}$ sodium sulfate, $7.0 \mathrm{mM}$ potassium dihydrogen phosphate, $7.0 \mathrm{mM}$ dipotassium hydrogen phosphate, and $25 \mathrm{mM}$ ammonium chloride all mixed in demonized water. The $\mathrm{pH}$ of the solution was adjusted to 6.0 through the addition of $1.0 \mathrm{mM}$ hydrochloric acid.
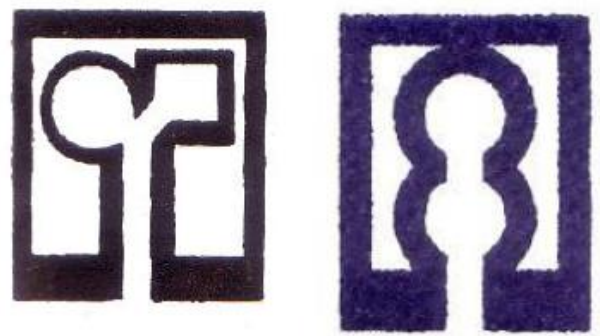

Figure 1. The design of paper based LOC using screen printing in both sides.

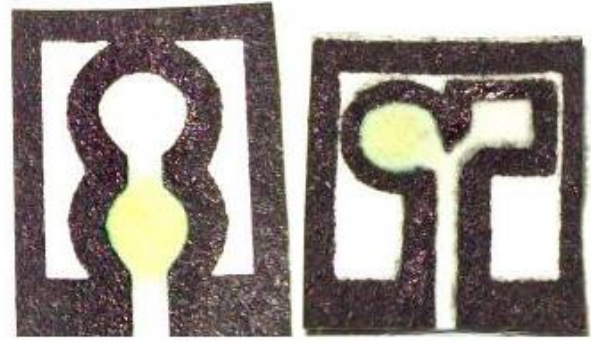


Figure 2. The paper based LOC with immobilised reagent in their well.
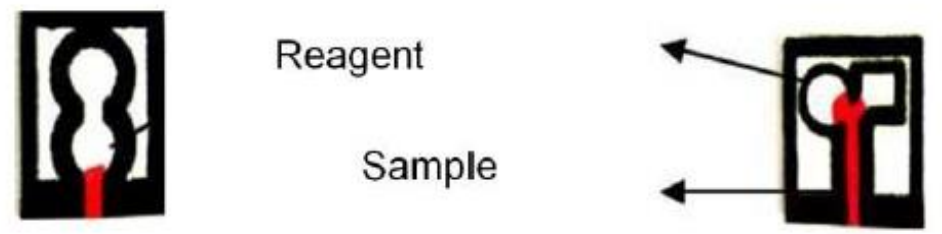

Figure 3. The measurement of test sample (red ink) in the paper based LOC.

The fluid filled the entire pattern within approximately 1-2 min, but the detection required 5-10 min for the paper to dry and for the color to fully develop. In these cases, we can observed the color changes corresponding roughly in intensity to the amount of urea, uric acid and protein in the test samples, in which the lowest concentrations define the lower limits to which these LOC can be used.For application in real clinical samples (urine, serum and saliva), the comparison with commercially available diagnostic tests to detect protein that are generally used in the clinical laboratory have also been employed.

\section{Results and Discussions}

\section{Paper based LOC profile}

Actually, paper strips have been used in clinical analysis for decades because they offer an inexpensive platform for colorimetric chemical testing [11]. Paper based LOC has characteristics that lead to miniaturized analysis that run by capillary action (e.g. without external pumping) with small volumes of fluids. In the case the paper chip can accommodate sample volume within 10$50 \mathrm{pL}$ (Figure 4). The methods show that the paper chip only needs very small samples, which suitable in clinical analysis. These methods suggest a path for the development of simple, inexpensive, and portable diagnostic test that may be useful in remote settings, and in particular, in less industrialized countries where simple test are becoming increasingly important for detecting disease and monitoring health $[12,13]$.

In the field, samples will not be measured under sterile conditions, and dust and dirt may contaminate the analysis. The combination of paper and capillary action provides a mechanism for separating particulates from a biological fluid. As a demonstration, the artificial urine samples stained with red ink were purposely contaminated with quantities of dirt and graphite powder at levels much higher than might be expect to encounter in the field. These particulates do not move up the channels with the sample and therefore do not interfere with the analysis (Figure 5).

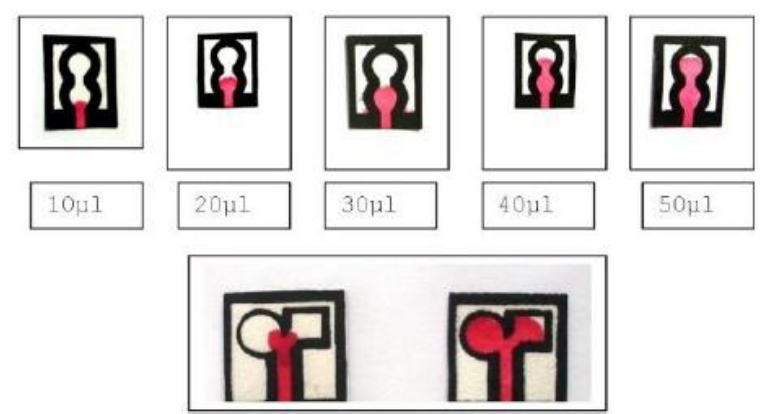

Figure 4. The volume of sample (red ink) in the paper based LOC.
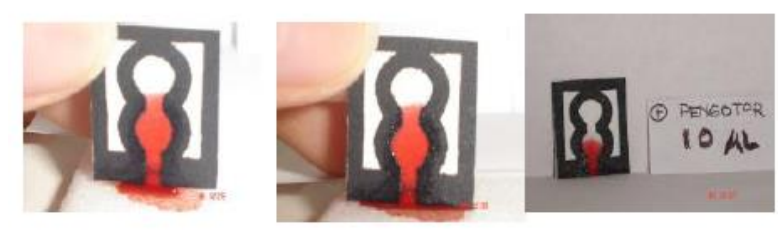

Figure 5. Detection of test sample contaminated with dirt and graphite powder.

For clinical samples e.g. whole blood, serum, urine and saliva, the compatibility of LOC towards the samples needs to be tested before analysis could be performed. Here, the channel in the paper based LOC provides capillary action for introducing sample from a biological fluid into reagent area. As demonstrated in Figure 6, the biological fluids move up easily via the channels towards the reagent area (Figure 6).

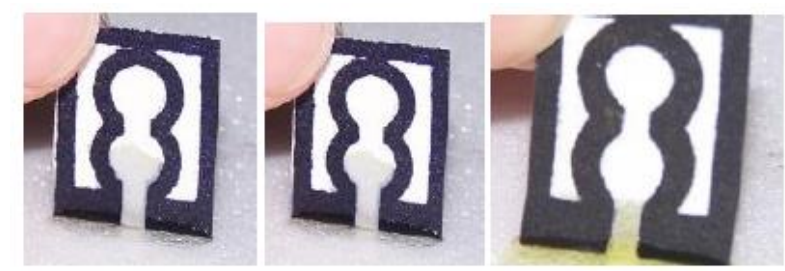

Figure 6. Capillary action in the LOC toward biological fluids $(\mathrm{A}=$ whole blood; $\mathrm{B}=$ saliva; $\mathrm{C}=$ urine). 
In the paper based LOC, the fluid or samples filled the entire pattern within approximately 1-2 min, but the detection required 5-10 $\min$ for the paper to dry and for the color to fully develop as shown in ( Figure 7) for protein. In these cases, we can observed the color changes corresponding roughly in intensity to the protein in the test samples, in which the concentrations of those analytes could be determine semi or quantitatively, within clinically relevant ranges for diagnostics.

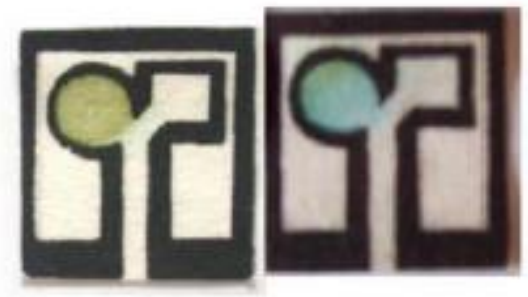

Figure 7. The color change of paper based LOC in the presence of analyte for protein.

The paper based LOC gave consistent results for the protein sensor regardless of storage temperature and time (when stored for 15 days both at $8^{\circ} \mathrm{C}$ and at $23^{\circ} \mathrm{C}$ and wrapped in aluminum foil).

\section{LOC response}

The response of paper based LOC towards clinical analyte protein in simulated sample is given in (Figure 8) respectively. In this direction, the paper chip gave consistent result for protein in simulated samples in the range 100-1000 ppm.

For simple measurement in semiquantitative manner, the paper chip can be used for detection protein in clinical samples according Tables 1 respectively. This kind of measurement could be used by doctors or nurses or even the patients he or herself for rapid evaluation of clinical status of corresponding analyte. Furthermore, this measurement could also be used for rapid screening and monitoring of health status of patient related to clinical analyte detected, where in this case protein is also detected.

Paper based LOC formats allow for the measurement of single analyte. This paper based LOC is also suitable for measuring multiple analytes in parallel and in a relatively short period of time, if the LOC designed for multiple analytes (Fig. 9). In the current design, for example, in one trial, one researcher was able to run 20 different samples within $20 \mathrm{~min}$, followed by another $10 \mathrm{~min}$ for the color to fully develop. An 18 min analysis of this type capable of measuring single analyte in 20 different samples may be efficient enough to use in high- throughput screens of larger sample pools.

\section{Application}

In order to evaluate the applicability of the paper based LOC for the analysis of real clinical samples for uric acid, protein and urea, several samples from patient in Dr. Subandi Hospital Jember were analyzed using LOC. In this direction, the LOC results were compared to clinical Lab results that have been performed by technicians in Dr. Subandi Hospital using commercially available clinical test for protein acid with protein using dipstick assays [14].The results of both methods for protein is listed in Tables 2 respectively. The results of this paper based LOC are comparable with the commercial clinical test that are usually employed in clinical laboratory.

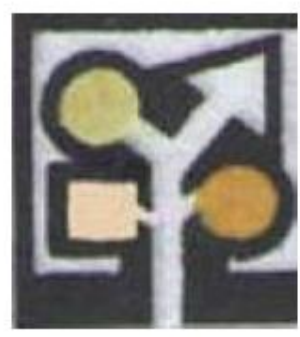

Figure 9 Protein in clinical sample

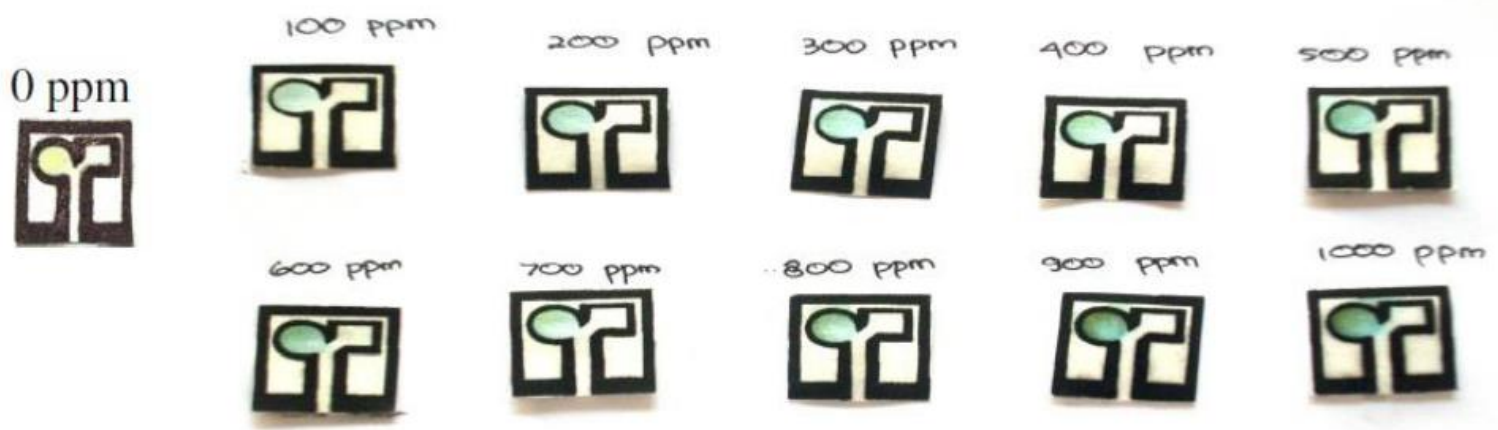

Figure 8. The color change of paper based LOC in the presence of protein (BSA) in simulated serum samples. 
Tabel 1 Indicator of protein detection

\begin{tabular}{ccc}
$\begin{array}{c}\text { Protein } \\
\text { Concentration }\end{array}$ & Catagory \\
\hline$<3.4 \mathrm{~g} / \mathrm{dL}$ & $\begin{array}{c}\text { Low conc of protein } \\
\text { (hipoprotein) }\end{array}$ \\
\hline $3.4-4.8 \mathrm{~g} / \mathrm{dL}$ & $\begin{array}{c}\text { Protein conc. within normal } \\
\text { range }\end{array}$ \\
\hline$>4.8 \mathrm{~g} / \mathrm{dL}$ & $\begin{array}{c}\text { High conc. of protein } \\
\text { (hiperprotein) }\end{array}$ & \begin{tabular}{c} 
Change to slighly blue \\
\hline
\end{tabular} \\
\hline
\end{tabular}

Tabel 2 The comparison results between LOC using serum samples with Clinical Lab (Dr. Subandi Hospital, Jember) using blood samples for protein analysis.

\begin{tabular}{|c|c|c|c|}
\hline $\begin{array}{l}\text { Clinical Lab. } \\
\text { Protein Conc. } \\
\text { (g/dL) }\end{array}$ & LOC response 1 & LOC Response 2 & Result \\
\hline $\begin{array}{l}\text { P1 } \\
1.9\end{array}$ & & 9ृदी & Low protein \\
\hline $\begin{array}{l}\mathrm{P} 2 \\
2.5\end{array}$ & 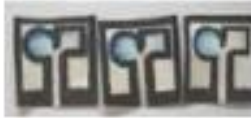 & & Low protein \\
\hline $\begin{array}{l}\text { P } 3 \\
34\end{array}$ & & & Normal \\
\hline $\begin{array}{l}\text { P } 4 \\
48\end{array}$ & & & Normal \\
\hline $\begin{array}{l}\text { P } 5 \\
6.8\end{array}$ & 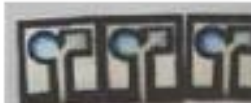 & & High protein \\
\hline $\begin{array}{l}\text { P } 6 \\
8.1\end{array}$ & GवG & & High protein \\
\hline
\end{tabular}




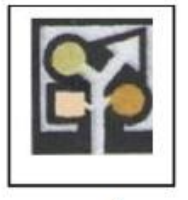

A

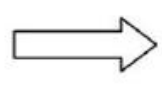

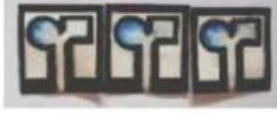

B
The lab on paper response toward analyte protein (from orange to blue) simultaneously in urine samples.

\section{Conclusion}

This work shows the simple method for patterning paper as paper based LOC for low cost sensor platform in clinical analysis and diagnostics. The LOC was fabricated using screen printing technology to create well-defined, millimeter-sized channels, comprising hydrophobic polymer bounded onto hydrophilic paper. The capability of paper chip for detection of importance clinical analytes, such as protein in urine and serum samples has been demonstrate successfully. The paper chip as a detection system is small, disposable, and easy to use and requires no external equipment, reagents, or power sources. This kind of diagnostic test system is attractive for use in the field, or remote area, as low-cost devices. Furthermore, the LOC could also be designed for multiple analytes detection simultaneously [Fig. 10], which is also under development in our Lab currently.

\section{Acknowledgement}

This work was supported by a grant from DP2M Higher Education, Department of National Education Republic of Indonesia via Hibah Kompetensi Batch I and Open University Jakarta via Afnidar. The author also thanks to $\mathrm{N}$. Kristiningrum, A.A Gani and N.W. Suwandari as well as other members of CBG (Kesit, Lunik and Ardini) for assisting this work.

\section{References}

[1] P. von Lode, Clin. Biochem. 2005, 38, 591 606.

[2] D. Mabey, R.W. Peeling, A. Ustianowski, M. D. Perkins, Nat. Rev. Microbiol. 2004, 2,231 240.
[3] A. S. Daar, H. Thorsteinsdottir, D. K. Martin, A. C. Smith, S. Nast, P. A. Singer, Nat. Genet. 2002, 32, 229 - 232.

[4] R. C. Willis, Anal. Chem. 2006, 78, 5261 5265.

[5] S.K. Sia, V.Linder, B.A. Parviz, A. Siegel, G. M. Whitesides, Angew. Chem. 2014, 116, 504 $-508$

[6] S.K. Sia, V.Linder, B.A. Parviz, A. Siegel, G. M. Whitesides, Angew. Chem. Int. Ed 2004, 43, $498-502$

[7] B. Kuswandi, Nuriman, D. N. Reinhoudt and W. Verboom, Anal. Chim. Acta, 2007, 601, 141-153.

[8] D. R. Reyes, D. Iossifidis, P-A. Auroux and A. Manz, Anal. Chem., 2002, 74(2), 2623-2636.

[9] M. J. Pugia, J. A. Lott, J. A. Profitt, T. K. Cast, J. Clin. Lab. Anal. 1999, 13, 180 - 187

[10] T. Brooks, C. W. Keevil, Lett. Appl. Microbiol. 1997, 24, 203 - 206.

[11] D. Mabey, R.W. Peeling, M. D. Perkins, Sex. Transm. Infect. 2001, 77, 397 - 398.

[12] P. Yager, T. Edwards, E. Fu, K. Helton, K. Nelson, M. R. Tam, B. H. Weigl, Nature 2006, 442, 412 - 418.

[13] Cypress Diagnostics, http://www.diagnostics. be/products/clinical/quicktest/ /Urine/ urine9.htm.

[14] W. J. Jhonson, W.W. Hagge, R.D. Wagoner, R.P. Dinapoli, J.W. Rosevear, Mayo, Clin. Proc., 1972. 47, 21-9 